\title{
Von Willebrand Disease: An Update
}

\section{Dipika Mohanty ${ }^{1 *}$, Shrimati Shetty ${ }^{2}$}

${ }^{1}$ Senior Consultant Haematologist and Chief of Laboratory Services, Apollo Hospitals, Bhubaneswar, Odisha, India

${ }^{2}$ National Institute of Immunohematology, 13th Floor, KEM Hospital MS Building, Mumbai-12, India

\begin{abstract}
Von Willebrand disease (VWD) is a common hereditary bleeding disorder, inherited either as an autosomally dominant or recessive trait. It is caused by a quantitative and/ or qualitative defect in the Von Willebrand Factor (VWF) which plays two critical roles in hemostasis i.e., platelet adhesion and aggregation to damaged endothelium, and also as a carrier for Factor VIII (FVIII) molecule which stabilizes FVIII in the circulation. It is a highly heterogeneous disease with bleeding ranging from mild bleeding tendencies to severe life threatening hemorrhage. Patients are classified as type 1, type 2 and type 3 , depending on the qualitative and quantitative defects in VWF antigen. Type 3 i.e., severe VWD has been reported to be the most prevalent subtype in Indian population due to two reasons i.e., higher degree of consanguinity in certain parts of the country and the fact that it is a hospital prevalence data and only patients with severe manifestations present themselves in the hospital. The most common bleeding symptoms in VWD reflect the characteristic defect in platelet adhesion and mucocutanous bleeding especially epistaxis, gum bleeding, menorrhagia and ecchymoses. Bleeding symptoms are of mild to moderate severity for patients with type 1 and few variants of type 2 VWD. However, life-threatening bleeding (Central nervous system, gastrointestinal bleed) can occur in type 3 and type 2 VWD patients, and rarely in type 1 VWD patients. Uncommon bleeding manifestations, such as hemarthrosis, and muscle haematomas are more common in severe deficiency, especially those who have type 3 VWD. Diagnosis, genetic counseling, carrier and antenatal diagnosis plays an important role in the comprehensive management of these cases.
\end{abstract}

Keywords: Von willebrand disease; Bleeding disorder

\section{Introduction}

Von Willebrand disease (VWD) is the common autosomal bleeding disorder caused by a quantitative and/ or qualitative defect in the Von Willebrand Factor (VWF), a large multimeric multifunctional plasma glycoprotein which plays a critical role in hemostasis. It is essential for platelet adhesion to damaged endothelium as well as platelet interactions at high shear stress. VWF has a direct role in thrombin and fibrin generation by acting as a carrier molecule for the cofactor FVIII [1].

The human VWF gene is located on the short arm of chromosome 12 and spans approximately $178 \mathrm{~Kb}$, comprising of 52 exons [2]. The mRNA has a length of $8.7 \mathrm{~kb}$ coding for precursor protein of 2813 amino acids (aa) that includes a 22 aa signal peptide, a propeptide of 741 aa and a mature subunit of 2050 aa. A partial unprocessed Pseudogene (VWFP) spanning to exon 23-34 has been localized on chromosome 22q11.22-q11.23 with 97\% homology which makes it difficult to detect mutations in these regions [3].

VWD encompasses a wide spectrum of bleeding disorders with severity ranging from moderate bleeding tendency to severe life threatening hemorrhage, estimated to affect approximately $0.5-1.6 \%$ of the population in the western countries. Patients with type 1 VWD present with mild bleeding tendency while type $3 \mathrm{VWD}$ represents the most severe form of the disease, characterized by undetectable levels of VWF in plasma. As per the western data the distribution of VWF types is $60-80 \%$ type $1,7-30 \%$ type 2 and $5-20 \%$ of type 3 VWD. However, the study of prevalence at this at NIIH, Mumbai, tertiary care center suggests $10.8 \%$ of the patients with inherited bleeding disorder have VWD with most prevalent subtype as type 3 i.e., $60 \%$ followed by type $2(19 \%)$ and $18 \%$ of type 1 may be due to hospital based data [4]. Patients are underdiagnosed due to the paucity of diagnostic facilities and unawareness of the disease entity in our country.

\section{Discovery and Identification of VWD}

In 1926, Dr. Erik von Willebrand of Helsinki reported in the literature several families who had, what he called hereditary pseudohemophilia His first case, a 5-year-old girl, Hjordis S., from Aland Islands who had bleeding symptoms was brought to Deaconess Hospital in Helsinki, Finland, in 1924 to be seen by Dr. Erik von Willebrand [5]. Both her parents had nose bleed and 11 siblings had bleeding symptoms. During her fourth menstrual period at the age of 13, Hjördis bled to death, similar to her four sisters who died of bleeding from the nose, wounds and/or the intestinal canal. He assessed 66 members of her family and reported in 1926 that this was a previously undescribed bleeding disorder that differed from hemophilia and exhibited i. mucocutaneous bleeding rather than hemarthrosis or deep vessel hemorrhage, ii. Autosomal inheritance rather than being linked to the $\mathrm{X}$ chromosome, iii. prolonged bleeding times by the Duke method, and iv. Normal clotting time. A similar bleeding disorder was reported four American groups [6].

It was observed that infusion of human fraction I-0 (purified fraction of Cohn- I) corrected both the plasma deficiency of antihemophilic factor (FVIII) and the prolonged bleeding time in such patients. Thus in 1950s, it became clear that a "plasma factor," (FVIII), was decreased in these patients and, the new factor causing the long bleeding time was called "von Willebrand factor". During the development of immunoassays, patients with VWD (in contrast to those who had Hemophilia A) were found to have reduced "FVIII-related antigen"

*Corresponding author: Dipika Mohanty, Senior Consultant Haematologist and Chief of Laboratory Services, Apollo Hospitals, Plot No 251, Old Sainik School Road, Bhubaneswar, Odisha, India 750015, Tel: 0674 6660413; E-mail: mohantydipika09@gmail.com

Received June 06, 2014; Accepted October 29, 2014; Published November 20,2014

Citation: Mohanty D, Shetty S (2014) Von Willebrand Disease: An Update. J Blood Disorders Transf 5: 238. doi: 10.4172/2155-9864.1000238

Copyright: ( $) 2014$ Mohanty D, et al. This is an open-access article distributed under the terms of the Creative Commons Attribution License, which permits unrestricted use, distribution, and reproduction in any medium, provided the original author and source are credited. 


\begin{tabular}{|c|c|c|c|c|c|}
\hline Country & Reference & No. of Patients & Type 1 (\%) & Type 2 (\%) & Type $3(\%)$ \\
\hline South Australia & Rodgers, et al. [50] & & 52 & 44 & 5 \\
\hline South Africa & Meiring, et al.[51] & & 38 & 58 & 4 \\
\hline Australia & Favaloro [52] & 1832 & 83.9 & 16.1 & 1.5 \\
\hline Italy & Federici, et al. [53] & & 55 & 40 & 5 \\
\hline USA & Werner, et al. [33] & 600 & & & \\
\hline South GDR & Lanke, et al. [27] & 111 & 76 & 12 & 12 \\
\hline \multirow{2}{*}{ Sweden } & Nilsson [5] & 106 families & 70 & 10 & 20 \\
\hline & Howard, et al. [7] & 116 & 71 & 23 & 6 \\
\hline Jordan & Awidi [54] & 65 & 59 & 29.5 & 11.5 \\
\hline India & Trasi, et al. [4] & 796 & 18 & 19 & 60 \\
\hline
\end{tabular}

Table 1: Frequency of different sub types of VWD obtained from various studies.

\begin{tabular}{|c|c|c|c|c|}
\hline Study & $\begin{array}{c}\text { Inherited bleeding } \\
\text { disorder (Total No.) }\end{array}$ & VWD No. (\%) & Type 1 No (\%) & Type 2 No. (\%) \\
\hline Gupta, et al. [38] & 224 & $64(28.6)$ & $14(21.9)$ & $28(43.7)$ \\
\hline Ahmad, et al. [55] & 1576 & $136(8.6)$ & $29(21.3)$ & 21(32.8) \\
\hline Kumar, et al. [37] & 230 & $40(17.3)$ & $17(42.5)$ & 33(24.3) \\
\hline Trasi, et al.[4] & 822 & $81(9.8)$ & $15(18.5)$ & $127.5)$ \\
\hline
\end{tabular}

Table 2: Spectrum of VWD in India.

(FVIIIR: Ag), now refered as VWF:Ag. Characterization of the proteins revealed that FVIII was the clotting protein deficient in Hemophilia A, and VWF was a separate "FVIII carrier protein" that resulted in the cofractionation of VWF and FVIII proteins in commercial concentrates. In 1971, ristocetin, an antibiotic isolated from the actinomycete species Nocardia lurida previously noted to cause thrombocytopenia, was reported to aggregate platelets in the presence of normal plasma but not in the presence of VWD plasma [7].

In 1926 Dr. Eric von Willebrand supposed heredity to be dominant gender-linked. However, in 1957 Nilsson suggested that the gene was autosomal dominant, which was confirmed by the pattern found by Zhang et al. in 1992 [8,9]. Since the 1980s, molecular and cellular studies have defined Hemophilia A and VWD more precisely. Patients diagnosed with VWD had a normal FVIII gene on the X chromosome, and an abnormal VWF gene on chromosome 12. The primary structure of VWF was determined in 1985 when the gene for VWF was independently cloned and sequenced by three groups $[2,10,11]$. Various designations of the disease such as pseudo haemophilia, constitutional thrombocytopathia and vascular hemophilia reflected not only the increasing knowledge of VWD but also the recognition of variant phenotypes. Several variant forms of VWF were recognized in the 1970s, now explained as the result of synthesis of an abnormal protein. Gene sequencing identified many of these patients as having a VWF gene mutation (Table 1).

\section{Structure of VWF protein}

The von Willebrand factor gene $(178 \mathrm{~kb})$ is located on chromosome 12 and comprises 52 exons. The primary structure of VWF has been determined both by direct amino acid sequence analysis and from the corresponding cDNA [12]. VWF has been cloned from endothelial cell cDNA libraries. Northern blotting analysis of endothelial cell RNA showed that VWF mRNA was about $9 \mathrm{~kb}$ (Table 2).

The VWF mRNA encodes a 2813-amino acid precursor (named prepro-VWF) with a mass of 350,000 daltons that contains a 22 -amino acid signal peptide, a 741-amino acid propeptide, and a 2050- amino acid mature subunit. Pro-VWF undergoes extensive post translational modification prior to secretion, which results in the formation of highly glycosylated, high molecular-weight multimer. Propeptide cleavage to yield the mature subunit with the formation of multimers ranging in size from the 500,000-dalton dimer to species of 210 million Daltons [13]. Several functional domains have been identified on the proVWF subunit [14]. Over $90 \%$ of the pre-pro-VWF contains 4 types of repeating (2-5 copies) domains $\mathrm{A}$ to $\mathrm{D}$ arranged in order-

\section{D1D2D'D3A1A2A3D4C1C2C3C4C5C6CK}

Two collagen-binding sites have been located on the mature VWF subunit $[15,16]$. The corresponding VWF fragments show structural homology and bind fibrillar collagen only in their native state-not when reduced and alkylated. There may be a third binding site for collagen, located on the propolypeptide, although in contrast to mature VWF, the propolypeptide is not detected in collagen-containing extracellular matrices [17]. Two heparin-binding sites were identified on the mature VWF subunit.

VWF is a protein that is assembled from identical subunits into linear strings of varying size referred to as multimers. These multimers can range from 0.5 to more than 20 million daltons in mass and $>2$ micrometers in length. Electron microscopic structure of VWF multimers after rotary shadowing appears as unbranched, loosely coiled, or extended thin strands [18]. The extended molecules are 1-3 $\mu \mathrm{m}$ long, a size approaching the diameter of a platelet and greatly surpassing the length of a fibronectin or fibrinogen molecule. The complex cellular processing consists of dimerization in the Endoplasmic Reticulum (ER), glycosylation in the ER and Golgi, multimerization in the Golgi, and packaging into storage granules. The latter two Scientific processes are under the control of the VWF propeptide (VWF pp), which is cleaved from VWF at the time of storage.

The electron micrographs of VWF multimers show that the subunits are organized in a head-to-head and tail-to-tail fashion and that the molecules are composed of globular regions connected by thin flexible rods. Circular dichroism studies of the multimers have demonstrated regions rich in IX helix and f3 pleated sheet structure, as well as a high percentage of random coil configurations.

These subunits show distinct characteristics:

1. An RGD (Arg-Gly-Asp) sequence, common to adhesive proteins at the $\mathrm{C}$ - terminal end. 
2. High content of Cys residues (8.3\%) involved in intra and interchain disulphide bonds.

3. Two remarkable disulphide in the $\mathrm{N}$ terminal region of the molecule, consisting of 30 cysteines between residues 283 and 695 ; and the other in the $\mathrm{C}$ terminal region has 18 Cys residues between 1908 and 2050 of which only a limited number are important in formation of the subunit dimers [19]. There are no detectable free sulphydral groups in the VWF, all cysteine residues thus being paired by inter or intra molecular bonds.

4. The presence of $18 \%$ Carbohydrates with $12 \mathrm{~N}$-linked and 10 O-linked glycosylation sites probably has a functional significance as they are easily accessible to specific ligands and can undergo conformational changes.

The A domains of VWF appear to be homologous to domains found in several other proteins such as complement factors B (20-24\% homology) and $\mathrm{C} 2$, chicken cartilage matrix protein, collagen type VI, and the a chains of the leukocyte adhesion molecules Mac-I, p 150, 95, and LFA-I. A strong similarity between short segments in domains $\mathrm{Cl}$ and $\mathrm{C} 2$ to a sequence in thrombospondin was found, but the segments are too short (10 amino acids) to conclude that the proteins are homologous. Interestingly, the same VWF regions (residues 11791237 and 1330-1397) are related to two segments in the Dictyostelium discoideum prestalk D11 protein and are included in a larger region of about 70 amino acids, which has the same 9 cysteine positions as found in the corresponding thrombospondin domain and is also present in procollagen types I and III [20]. The D domains of VWF show homologies to both invertebrate and vertebrate vitellogenins. The biological significance of the homologies and similarities of VWF to other proteins described above is not known. These may have arisen by repeated gene segment duplication and exon shuffling

\section{Genetics of VWD}

The molecular and cellular studies have defined hemophilia A and VWD more precisely in late 1980s. Severe VWD patients were found to have a normal FVIII gene on the X chromosome, and an abnormal VWF gene on chromosome 12. The VWF gene has been localized to chromosome 12 [2,11], and a partial pseudogene i.e. VWFP has been identified on chromosome 22 . The gene is $178 \mathrm{~kb}$ in length and contains 52 exons. The signal peptide and propolypeptide are encoded by 17 exons, and the mature subunit and 3 ' noncoding region are encoded by the remaining 35 exons. Segments that encode homologous domains have similar exonic structures, consistent with their evolution by gene segment duplication [3].

\section{Classification and Molecular pathology of VWD}

VWD is classified on the basis of criteria developed by the VWF Subcommittee of the ISTH, first published in 1994 and revised in $2006[21,22]$. The previous classification restricted VWD to mutations within the VWF gene but this criterion has been dropped from the 2006 classification as only a small fraction of patients can be practically verified. The classification emphasizes the VWF protein phenotype of the patient but is independent on genotypic data, because protein characteristics are accessible through commonly available laboratory tests, whereas the underlying genetic defects are not. Some VWF gene mutations, alone or in combination, have complex effects and give rise to mixed VWD phenotypes.

VWD is classified into three major categories: partial quantitative deficiency (type 1), qualitative deficiency (type 2), and total deficiency (type 3$)$. There are two major levels of classification: primary $(1,2,3)$ and secondary $(\mathrm{A}, \mathrm{B}, \mathrm{M}, \mathrm{N})$. Type $2 \mathrm{VWD}$ is divided further into four variants $(2 \mathrm{~A}, 2 \mathrm{~B}, 2 \mathrm{M}, 2 \mathrm{~N})$ on the basis of details of the phenotype. Before the publication of the revised classification of VWD, VWD subtypes were classified using Roman numerals (types I, II, and III), generally corresponding to types 1, 2, and 3 in the 1994 classification, and within type II several subtypes existed (designated by adding sequential letters of the alphabet; i.e., II-A through II-I). Most of the latter VWD variants were amalgamated as type 2A in the 1994 classification, with the exception of type $2 \mathrm{~B}$ (formerly II-B) for which a separate new classification was created and a new subtype (2M) was created to include variants with decreased platelet dependent function (VWF :RCo) but no significant decrease of higher molecular weight VWF multimers.

Presences of excess of ultralarge multimers are known to be prothrombotic in nature. These are secreted by endothelial cells and remain adhered to platelets until cleavage by ADAMTS-13. As such In ADAMTS-13-deficient congenital and autoantibody-mediated Thrombotic Thrombocytopenic Purpura (TTP), there is reduced cleavage of ultra large VWF multimers.

Type 1 VWD: Type 1 VWD refers to partial quantitative deficiency of VWF. The plasma VWF levels in type 1 VWD are low, and the remaining VWF mediates normal platelet adhesion and FVIII binding. Laboratory evaluation shows concordant decreases in VWF protein concentration (VWF: Ag) and assays of VWF function (VWF: RCo) with no significant decrease in large VWF multimers. Usually, in type 1 VWD, the FVIII/VWF: Ag ratio is 1.5-2.0. In type 1 VWD patients, this results in FVIII being normal, or mildly decreased, and not reduced as much as the VWF. Plasma VWF may contain mutant subunits, but has normal functional activity relative to antigen level. Reduced secretion in type 1VWD might be caused by VWF mutations affecting gene expression; particularly severe, highly penetrant forms of type $1 \mathrm{VWD}$ may be caused by dominant VWF mutations that interfere with the intracellular transport of dimeric proVWF or that promote the rapid clearance of VWF from the circulation [23]. Patient who have such mutations usually have VWF levels $<20 \mathrm{IU} / \mathrm{dL}$. Mutations have been identified in $60-65 \%$ of individuals with type 1 VWD [24]

Classification of VWD Vicenza as type 1 or type $2 \mathrm{M}$ has been controversial VWD Vicenza is characterized by VWF: Ag levels of 6-12 IU/dL, normal platelet VWF, and ultra-large plasma VWF multimers $[25,26]$. VWD Vicenza may be an extreme example of increased VWF clearance. The VWF level is measurable, whereas the levels of VWF: RCo and VWF: Ag are decreased proportionately. Therefore, this variant is classified under VWD type 1 .

VWD Vicenza is caused by the heterozygous mutation Arg1205His in the D3 domain. Expression studies suggest efficient secretion, low VWF concentration and ultra-large multimers in patient plasma that do not reflect a biosynthetic defect but reduction in half life ( 4.4 fold) after desmopressin when compared with healthy controls. Rapid clearance decreases the time during which a large, circulating VWF multimer can be cleaved by ADAMTS-13. Consequently, increased clearance should shift the plasma VWF multimer distribution toward that secreted initially from endothelial cells. Under these conditions, plasma VWF should include ultra-large species and show relatively little subunit proteolysis, and both features are characteristic of VWD Vicenza [26].

Increased susceptibility of VWF to proteolytic cleavage may also modulate the severity of VWD type 1 . The substitution Tyr1584Cys slightly increases the susceptibility of VWF to cleavage by ADAMTS-13, which may impair platelet plug formation with no reduction in 
intravascular survival of VWF. This has been identified in 3-25\% of patients with VWD type 1, compared with less than $2 \%$ of healthy controls [27]. The Tyr1584Cys mutation is associated weakly, which is consistent with increased intracellular retention of the recombinant 1584 Cys variant. The 1584 Cys variant does not co-segregate consistently with a low VWF level or with bleeding symptoms in affected families, suggesting that it is a relatively modest risk factor for VWD type 1 . It is clear that several distinct mechanisms can cause VWD type 1, and some can be distinguished by suitable testing. For example, variants associated with rapid clearance may be identified by the characteristic response to a test dose of desmopressin. The clinical significance of this heterogeneity is under investigation, which could lead to changes in the classification of VWD.

Type 2 VWD: VWD type 2 includes qualitative defects of VWF. VWD type 2 is subdivided based on specific functional and structural defects that impair platelet adhesion or FVIII binding. Bleeding symptoms in type 2 VWD are often thought to be more severe than in type 1 VWD.

Type 2A VWD: refers to qualitative variants in which VWFdependent platelet adhesion is decreased because the proportion of large VWF multimers is decreased. Levels of VWF: Ag and FVIII may be normal or modestly decreased, but VWF function is abnormal as shown by markedly decreased VWF: RCo Type 2A VWD may be caused by mutations that interfere with the assembly or secretion of large multimers or by mutations that increase the susceptibility of VWF multimers to proteolytic degradation in the circulation. The deficit of large multimers predisposes persons to bleed [28].

At present, the discrimination between type $2 \mathrm{~A}$ variants requires high-resolution multimer gel electrophoresis or gene sequencing, and these techniques are not widely available.

The location of type 2A VWD mutations sometimes can be inferred from high-resolution VWF multimer gels. For example, mutations that primarily reduce multimer assembly lead to the secretion of multimers that are too small to engage platelets effectively and therefore are relatively resistant to proteolysis by ADAMTS13. Homozygous mutations in the propeptide impair multimer assembly in the Golgi and give rise to a characteristic "clean" pattern of small multimers that lack the satellite bands usually associated with proteolysis; this pattern was initially described as "type IIC" VWD [29]. Heterozygous mutations in the cystine knot (CK) domain can impair dimerization of proVWF in the ER and cause a recognizable multimer pattern originally referred to as "type IID". A mixture of monomers and dimers arrives in the Golgi, where the incorporation of monomers at the end of a multimer prevents further elongation. As a result, the secreted small multimers contain minor species with an odd number of subunits that appear as faint bands between the usual species that contain an even number of subunits. Heterozygous mutations in cysteine residues of the D3 domain also can impair multimer assembly, but these mutations often also produce an indistinct or "smeary" multimer pattern referred to as "type IIE". In contrast to mutations that primarily affect multimer assembly, mutations within or near the A2 domain of VWF cause type 2A VWD that is associated with markedly increased proteolysis of the VWF subunits. These mutations apparently interfere with the folding of the A2 domain and make the Tyr1605-Met1606 bond accessible to ADAMTS13 even in the absence of increased fluid shear stress. Two subgroups of this pattern have been distinguished: group I mutations enhance proteolysis by ADAMTS13 and also impair multimer assembly, whereas group II mutations enhance proteolysis without decreasing the assembly of large VWF multimers. Computer modeling of domain A2 suggests that group I mutations affect both assembly and proteolysis, because group I mutations have a more disruptive effect on the folding of domain A2 than do group II mutations [30].

Type 2B VWD: includes qualitative variants with increased affinity for platelet GPIb. This type is characterized by increased ristocetininduced platelet aggregation (RIPA) at low concentrations of ristocetin, because of enhanced interaction of the mutant VWF with platelet GPIb is caused by mutations that pathologically increase platelet-VWF binding, which leads to the proteolytic degradation and depletion of large, functional VWF multimers. Circulating platelets also are coated with mutant VWF, which may prevent the platelets from adhering at sites of injury [31].

Although laboratory results for type $2 \mathrm{~B}$ VWD may be similar to those in type $2 \mathrm{~A}$ or type $2 \mathrm{M} \mathrm{VWD}$, patients who have type $2 \mathrm{~B}$ VWD typically have thrombocytopenia that is exacerbated by surgery, pregnancy, or other stress. The thrombocytopenia probably is caused by reversible sequestration of VWF -platelet aggregates in the microcirculation. These aggregates are dissolved by the action of ADAMTS13 on VWF, causing the characteristic decrease of large VWF multimers and the prominent satellite banding pattern that indicates increased proteolytic degradation [32]. The diagnosis of type 2B VWD depends on finding abnormally increased Ristocetin Induced Platelet Aggregation (RIPA) at low concentrations of ristocetin.

Type 2M VWD: "M" represents "multimer." Type 2M VWD includes variants with decreased VWF -dependent platelet adhesion that is not caused by the absence of high-molecular-weight VWF multimers (which may or may not have other aberrant structure). Instead, type $2 \mathrm{M}$ VWD mutations reduce the interaction of VWF with platelet GPIb or with connective tissue and do not substantially impair multimer assembly. Screening laboratory results in type $2 \mathrm{M}$ VWD and type 2A VWD are similar, and the distinction between them depends on multimer gel electrophoresis.

Mutations in type 2M VWD have been identified in domain A1, where they interfere with binding to platelet GPIb. One family has been reported in which a mutation in VWF domain A3 reduces VWF binding to collagen, thereby reducing platelet adhesion and possibly causing type $2 \mathrm{M}$ VWD.

Type 2N VWD Subtype 2N VWD was defined, with "N" representing "Normandy" where the first individuals were identified, with decreased FVIII due to VWF defects of FVIII binding.

It is caused by VWF mutations that impair binding to FVIII, lowering FVIII levels so that type $2 \mathrm{~N}$ VWD masquerades as an autosomal recessive form of hemophilia A. In typical cases, the FVIII level is less than 10 percent, with a normal VWF: Ag and VWF: RCo. Discrimination from hemophilia A may require assays of FVIII-VWF binding. Certain DDAVP studies have demonstrated that the halflife of FVIII in these patients is significantly reduced (approximately 2-3h). Mutations resulting in 2N VWD are listed in the VWF mutation database (http://www.ragtimedesign.com/VWF /mutation/).

Type 3 VWD: Type 3 VWD is characterized by undetectable VWF protein and activity, and FVIII levels usually are very low (1-9 IU/dL). Patients with type 3 VWD manifests with severe mucocutaneous and musculoskeletal bleeding due to absence of VWF: Ag thus, referred as severe VWD. Nonsense and frameshift mutations commonly cause type $3 \mathrm{VWD}$, although large deletions, splice-site mutations, and missense mutations were also reported. Mutations are distributed throughout the VWF gene, and most are unique to the family in which 
they were first identified. Gene conversion as causative mechanism in severe VWD has been reported by several authors.

Pseudo-VWD is a platelet defect (glycoprotein Ib receptor defect) that mimics type $2 \mathrm{~B}$ VWD. The characteristic laboratory features are increased platelet-VWF binding leading to proteolytic degradation and depletion of HMW functional VWF multimers.

\section{Prevalence}

VWD encompasses a wide array of bleeding manifestations with prevalence estimated as high as $0.7-1.6 \%$ in general population in Western countries $[33,34]$. The method used to estimate prevalence is of major importance, i.e. using referral-based prevalence or populationbased prevalence.

Referral-based prevalence: Referral-based prevalence is the number of patients seen at specialized centers divided by the total population served by those centers. Referral-based prevalence is dependent on several factors such as diagnostic facilities, subtyping VWD on the laboratorial evaluation, severity of bleeding and the actual population of the bleeding patients presenting in those centers. Estimates of 3-4 per 100,000 populations have been made in UK and 7 in Switzerland. The true prevalence of VWD is probably higher than suggested by available estimates.

Population-based prevalence: The prevalence of VWD in general population is determined by employing standard criteria for bleeding symptoms, family history and laboratory values. In such survey, patients with less severity of bleeding (like bruises or eccymosis and menorrhagia which is generally considered as familial), asymptomatic and severe bleeders can be detected.

The distribution of VWD types is $60-80 \%$ type 1 VWD, 7-30\% type 2 and $5-20 \%$ type 3 VWD. These values are very approximate since they depend strongly on the methods of assessment of patient distribution and the criteria for diagnosis, especially type 1. For instance, the Dutch and the French populations report a much lower prevalence of VWD type 1 due to more stringent inclusion criteria for VWD type 1 diagnosis. As the facility of multimer analysis for subtyping is not available at many centers for correct classification of VWD, many of the type 2 cases are classified as type 1. Estimates of prevalence of VWD type 3 include 0.55 for Italy 1.38 for North America, 3.12 for Sweden and 3.2 for Israel per million population $[35,36]$.

\section{Spectrum of VWD in India}

Very few laboratories in India work on diagnosis of VWD. Reports are available on incidence of VWD from tertiary care centers or hospitals [37-39]. As per the Western data the distribution of VWD types is $60-80 \%$ type $1,7-30 \%$ type 2 and $5-20 \%$ of type 3 VWD. However, as opposed to Western data there was a reverse trend in the prevalence of these different subtypes' reports from India. Based on hospital data it has been observed that type 3 is the predominant subtype (60\%) followed by (19\%) type 2 and (18\%) type 1 VWD [4]. The reasons for the contrasting prevalence of VWD between our country and the Western countries may be that only the severe bleeders are being reported to the hospital, while the milder ones are totally underdiagnosed. Another study from North India has recorded a prevalence of $73 \%$ type 2 VWD, $32.8 \%$ type 3 VWD and $29 \%$ type 1 VWD. This difference of percentage in different Institutes implies importance of multimer study in VWD patients, which otherwise is undiagnosed due to normal APTT, FVIII assay and RIPA.

\section{Acquired Von Willebrand Disease}

In contrast to congenital Von Willebrand Disease acquired Von Willebrand Disease is rare. There is no accurate estimate of the prevalence. However, 300 cases have been reported [40]. In 1968, Simone et al described first time AVWD in a boy of 7 yrs with SLE [41]. A high degree of suspicion of AVWD should lead to an appropriate investigation in a patient with an acquired bleeding disorder. A good clinical history is important in distinguishing between congenital or acquired VWD. Usually occurs in elderly patients. The patient usually present with mucocutareous bleeding with no history of bleeding in the past or any family history of bleeding. The pathogenesis of this disorder remains less understood. It may be due to development of autoantibody directed against the VWF, leading to a rapid clearance from the circulation or interference with its function. Another non immunologic mechanism may be that due to adsorption of VWF by tumor cells, this factor may be lowered [42].

Usually this disorder is associated with myelo- or lymphoproliferative disorder or auto immune disease. Drug induced AVWD has been reported with Ciprofloxacin, valproic acid and griseofulvin [43]. The severity of bleeding varies considerably amongst the patients. Laboratory testing includes bleeding time, PT \& APTT and specific tests for VWD like VWF antigen and restocetin co-factor, VWF multiner analysis.

The therapy for management of this disorder includes desmopressin and plasma derived factor VIII concentrate containing VWF. But most important is the treatment of associated disorders. Intravenous immunoglobulins also have been used for treating these cases.

\section{Diagnosis}

An accurate subtyping of VWD requires a series of laboratory investigations which includefactorVIII(FVIII) coagulant activity(FVIII: C), ristocetin induced platelet aggregation (RIPA), von Willebrand factor (VWF) antigen (VWF: Ag) and VWF ristocetin cofactor activity (VWF: RCo), VWF multimer analysis, VWF: collagen binding assay (VWF:CBA), VWF : FVIII binding assay (VWF: FVIIIBA). Mutation analysis is required in some cases for an accurate subtyping of VWD. Bleeding assessment tool (BAT) serves as an important screening test and also helps in subtyping [44]. Often there is an overlap in the laboratory diagnosis of type $2 \mathrm{~B}$ VWD and platelet type VWD, wherein there is an increased affinity of VWF to the platelets. The genetics of these two disorders is different; the former is due to genetic defects in VWF, while the latter is due to a defect in the platelet receptor GP1b/IX. The differential diagnosis is offered by mixing studies.

\section{Genetic diagnosis}

Mutation detection in VWF gene is quite challenging due to its large size, heterogeneous nature of mutations and the presence of a partial unprocessed pseudogene in chromosome 22. Pseudogene can further complicate molecular genetic studies of VWF gene, as amplification of the gene by PCR may simultaneously amplify the pseudogene that shares similar sequences known as PCR bias or amplification bias and can introduce artifacts to molecular experiments targeted at functional genes. Sequence differences between the highly polymorphic gene and pseudogene are generally exploited to design oligonucleotide primers for use in PCR to selectively amplify sequences corresponding to exons 23-34 of VWF gene.

There are few previous reports on multiple nucleotide substitutions in a limited region of the VWF gene comprising the 3' part of intron 27 
and the 5' part of exon 28 in patients with VWD. The heterogeneous extent of these mutated regions and their homology to sequences of the VWF. Pseudogene suggests multiple recombinational events between the true gene and the VWFP [45]. This can result in different phenotypic expression depending on the length of the gene conversion or whether the conversion is homozygous, heterozygous or compound heterozygous.

The spectrum of VWF gene mutations that cause VWD is similar to that of many other human genetic diseases and includes large deletions, frame shifts from small insertions or deletions, splice-site mutations, nonsense mutations causing premature termination of translation, and missense mutations affecting single amino acid residues. A database of VWF mutations and polymorphisms has been compiled for the International Society on Thrombosis and Haemostasis (ISTH) and is maintained for online access at the University of Sheffield (http://www. shef.ac.uk/VWF/index.html). Mutations causing VWD have been identified throughout the VWF gene. In contrast to hemophilia $\mathrm{A}$, in which a single major gene rearrangement causes a large fraction of severe disease, no such recurring mutation is common in VWD. There is a good correlation between the location of mutations in the VWF gene and the subtype of VWD. In selected families, this information can facilitate the search for VWF mutations by DNA sequencing. The routine genetic diagnosis can also be performed by indirect gene tracking technique using the polymorphic markers of VWF gene $[46,47]$.

\section{Management}

Treatment depends on the VWD type or specific subtype (e.g., type $2 \mathrm{~A}, 2 \mathrm{~B}, 2 \mathrm{M}$, or $2 \mathrm{~N}$ ) and on the basis of symptoms or clinical severity. are

Different strategies to prevent or control bleeding in VWD patients

1. To increase plasma concentration of VWF by releasing endogenous VWF stores through stimulation of endothelial cells with DDAVP.

2. To replace VWF by using human plasma-derived, viralinactivated concentrates.

3. Use of agents that promote hemostasis and wound healing but do not substantially alter the plasma concentration of VWF.

Depending on the type and severity of VWD, the severity of the hemostatic challenge, and the nature of the actual or potential bleeding, patient may be given appropriate choice of one or all the agents to control bleeding. prophylaxis (Infusions of VWF to prevent bleeding episodes) in case of severe VWD patient are less frequently required in patients as compared to patients with severe hemophilia. The CDC Universal Data Collection Project Web site (http://www2a.cdc.gov/ ncbddd/htcweb/) reports that 45 percent of patients who have severe hemophilia A use some type of prophylaxis, continuous or intermittent, compared with 10 percent of patients who have severe VWD. Risks and benefits of prophylaxis should be carefully weighed when considering long-term therapy for VWD

Different types of FVIII/VWF concentrates are currently available in the market. The difference between these concentrates is the VWF structure and ratios of VWF: RCo to VWF: Ag and FVIII to VWF which can occur during the manufacturing and viral inactivation process $[48,49]$. Generally those concentrates which have VWF (VWF: RCo) and FVIII content having VWF/FVIII ratio equal or higher than 1 is the preferred choice. These have not been analyzed for their contents and for their clinical impact. Other treatment products include Desmopressin, antifibrinolytics and cryoprecipitate. Hormonal therapy along with antifibrinolytics is the main mode of treatment in women with VWD and menorrhagia. Type 3 VWD generally does not respond to desmopressin. Replacement therapy with factor concentrates having FVIII and VWF is the treatment option for type 3 and type $2 \mathrm{~B}$. Recombinant VWF factors are currently undergoing clinical trials.

\section{References}

1. De Meyer SF, Deckmyn H, Vanhoorelbeke K (2009) von Willebrand factor to the rescue. Blood 113: 5049-5057.

2. Ginsburg D, Handin RI, Bonthron DT, Donlon TA, Bruns GA, et al. (1985) Human von Willebrand factor (VWF): isolation of complementary DNA (cDNA) clones and chromosomal localization. Science 228: 1401-1406.

3. Mancuso DJ, Tuley EA, Westfield LA, Lester-Mancuso TL, Le Beau MM, et al. (1991) Human von Willebrand factor gene and pseudogene: structural analysis and differentiation by polymerase chain reaction. Biochemistry 30: 253-269.

4. Trasi S, Shetty S, Ghosh K, Mohanty D (2005) Prevalence and spectrum of von Willebrand disease from western India. Indian J Med Res 121: 653-658.

5. Nilsson IM (1999) Commentary to Erik von Willebrand's original paper from 1926 'Hereditär pseudohemofili'. Haemophilia 5: 220-221.

6. Holmberg L, Nilsson IM (1975) Von Willebrand's disease. Annu Rev Med 26 33-44.

7. Howard MA, Firkin BG (1971) Ristocetin--a new tool in the investigation of platelet aggregation. Thromb Diath Haemorrh 26: 362-369.

8. Zhang ZP, Lindstedt M, Falk G, Blombäck M, Egberg N, et al. (1992) Nonsense mutations of the von Willebrand factor gene in patients with von Willebrand disease type III and type I. Am J Hum Genet 51: 850-858.

9. Zhang ZP, Falk G, Blomback M, Egberg N, Anvret M (1992) Identification of a new nonsense mutation in the von Willebrand factor gene in patients with von Willebrand disease type III. Hum Mol Genet 1:61-62.

10. Sadler JE, Shelton-Inloes BB, Sorace JM, Harlan JM, Titani K, et al. (1985) Cloning and characterization of two cDNAs coding for human von Willebrand factor. Proc Natl Acad Sci U S A 82: 6394-6398.

11. Verweij CL, de Vries CJ, Distel B, van Zonneveld AJ, van Kessel AG, et al (1985) Construction of cDNA coding for human von Willebrand factor using antibody probes for colony-screening and mapping of the chromosomal gene. Nucleic Acids Res 13: 4699-4717.

12. Titani K, Kumar S, Takio K, Ericsson LH, Wade RD, et al. (1986) Amino acid sequence of human von Willebrand factor. Biochemistry 25: 3171-3184.

13. Wagner DD, Marder VJ (1983) Biosynthesis of von Willebrand protein by human endothelial cells. Identification of a large precursor polypeptide chain. J Biol Chem 258: 2065-2067.

14. Pietu G, Meulien P, Cherel G, Diaz J, Baruch D, et al (1989) Production in Escherichia coli of a biologically active subfragment of von Willebrand factor corresponding to the platelet glycoprotein $\mathrm{lb}$, collagen and heparin binding domains. Biochem Biophys Res Commun 164: 1339-1347.

15. Kalafatis M, Takahashi Y, Girma JP, Meyer D (1987) Localization of a collageninteractive domain of human von Willebrand factor between amino acid residues Gly 911 and Glu ,365. Blood 70: 1577-1583.

16. Pareti FI, Niiya K, McPherson JM, Ruggeri ZM (1987) Isolation and characterization of two domains of human von Willebrand factor that interact with fibrillar collagen types I and III. J Biol Chem 262: 13835-13841.

17. Takagi J, Kasahara K, Sekiya F, Inada Y, Saito Y (1989) A collagen-binding glycoprotein from bovine platelets is identical to propolypeptide of von Willebrand factor. J Biol Chem 264: 10425-10430.

18. Fowler WE, Fretto LJ, Hamilton KK, Erickson HP, McKee PA (1985) Substructure of human von Willebrand factor. J Clin Invest 76: 1491-1500.

19. Marti T, Rösselet SJ, Titani K, Walsh KA (1987) Identification of disulfidebridged substructures within human von Willebrand factor. Biochemistry 26 8099-8109.

20. Hunt LT, Barker WC (1987) von Willebrand factor shares a distinctive cysteinerich domain with thrombospondin and procollagen. Biochem Biophys Res Commun 144: 876-882. 
21. Sadler JE (1994) A revised classification of von Willebrand disease. For the Subcommittee on von Willebrand Factor of the Scientific and Standardization Committee of the International Society on Thrombosis and Haemostasis. Thromb Haemost 71: 520-525.

22. Sadler JE, Budde U, Eikenboom JC, Favaloro EJ, Hill FG, et al. (2006) Update on the pathophysiology and classification of von Willebrand disease: a report of the Subcommittee on von Willebrand Factor. J Thromb Haemost 4: 2103-2114

23. Casonato A, Pontara E, Sartorello F, Cattini MG, Sartori MT, et al. (2002) Reduced von Willebrand factor survival in type Vicenza von Willebrand disease. Blood 99: 180-184

24. James PD, Notley C, Hegadorn C, Leggo J, Tuttle A, et al. (2007) The mutationa spectrum of type 1 von Willebrand disease: Results from a Canadian cohort study. Blood 109: 145-154.

25. Castaman G, Novella E, Castiglia E, Eikenboom JC, Rodeghiero F (2002) A novel family with recessive von Willebrand disease due to compound heterozygosity for a splice site mutation and a missense mutation in the von Willebrand factor gene. Thromb Res 105: 135-138.

26. Mannucci PM, Lombardi R, Castaman G, Dent JA, Lattuada A, et al. (1988) von Willebrand disease "Vicenza" with larger-than-normal (supranormal) von Willebrand factor multimers. Blood 71: 65-70.

27. Lanke E, Johansson AM, Hallden C, Lethagen S (2005) Genetic analysis of 31 Swedish type 1 von Willebrand disease families reveals incomplete linkage to the von Willebrand factor gene and a high frequency of a certain disease haplotype. J Thromb Haemost 3: 2656-2663.

28. Ruggeri ZM, Zimmerman TS (1980) Variant von Willebrand's disease: characterization of two subtypes by analysis of multimeric composition of factor VIII/von Willebrand factor in plasma and platelets. J Clin Invest 65: 1318-1325.

29. Schneppenheim R, Thomas KB, Krey S, Budde U, Jessat U, et al. (1995) Identification of a candidate missense mutation in a family with von Willebrand disease type IIC. Hum Genet 95: 681-686.

30. O'Brien LA, Sutherland JJ, Hegadorn C, Benford K, Racz H, et al. (2004) A novel type 2A (Group II) von Willebrand disease mutation (L1503Q) associated with loss of the highest molecular weight von Willebrand factor multimers. J Thromb Haemost 2: 1135-1142.

31. Lankhof H, Damas C, Schiphorst ME, IJsseldijk MJ, Bracke M, et al. (1997) Functional studies on platelet adhesion with recombinant von Willebrand factor type 2B mutants R543Q and R543W under conditions of flow. Blood 89: 27662772.

32. Casonato A, Sartori MT, de Marco L, Girolami A (1990) 1-Desamino-8-D-arginine vasopressin (DDAVP) infusion in type IIB von Willebrand's disease: shortening of bleeding time and induction of a variable pseudothrombocytopenia. Thromb Haemost 64: 117-120.

33. Werner EJ, Broxson EH, Tucker EL, Giroux DS, Shults J, et al. (1993) Prevalence of von Willebrand disease in children: a multiethnic study. J Pediatr 123: 893-898.

34. Rodeghiero F, Castaman G, Dini E (1987) Epidemiological investigation of the prevalence of von Willebrand's disease. Blood 69: 454-459.

35. Mannucci PM, Bloom AL, Larrieu MJ, Nilsson IM, West RR (1984) Atherosclerosis and von Willebrand factor. I. Prevalence of severe von Willebrand's disease in western Europe and Israel. Br J Haematol 57: 163-169.

36. Weiss HJ, Sussman II (1986) A new von Willebrand variant (type I, New York) increased ristocetin-induced platelet aggregation and plasma von Willebrand factor containing the full range of multimers. Blood 68: 149-156.

37. Kumar S, Kishore R, Gupta V, Jain M, Shukla J (2010) Prevalence and spectrum of von Willebrand disease in Eastern Uttar Pradesh. Indian J Pathol Microbiol 53: 486-489.

38. Gupta PK, Ahmed RP, Sazawal S, Choudhry VP, Saxena R (2005) Relatively high frequency of VWD types 3 and 2 in a cohort of Indian patients: the role of multimeric analysis. J Thromb Haemost 3: 1321-1322.

39. Srivastava A, Rodeghiero F (2005) Epidemiology of von Willebrand disease in developing countries. Semin Thromb Hemost 31: 569-576.

40. Tefferi A, Nichols WL (1997) Acquired von Willebrand disease: concise review of occurrence, diagnosis, pathogenesis, and treatment. Am J Med 103: 536540 .

41. Simone JV, Cornet JA, Abildgaard CF (1968) Acquired von Willebrand's syndrome in systemic lupus erythematosus. Blood 31: 806-812.
42. Agrawal AK, Golden C, Matsunaga A (2011) Acquired von Willebrand disease in an osteosarcoma patient. J Pediatr Hematol Oncol 33: 622-623.

43. Eberl W, Budde U, Bentele K, Christen HJ, Knapp R, et al. (2009) Acquired von Willebrand syndrome as side effect of valproic acid therapy in children is rare. Hamostaseologie 29: 137-142.

44. Rydz N, Swystun LL, Notley C, Paterson AD, Riches JJ, et al. (2013) The C-type lectin receptor CLEC4M binds, internalizes, and clears von Willebrand factor and contributes to the variation in plasma von Willebrand factor levels. Blood 121: 5228-5237.

45. Surdhar GK, Enayat MS, Lawson S, Williams MD, Hill FG (2001) Homozygous gene conversion in von Willebrand factor gene as a cause of type 3 von Willebrand disease and predisposition to inhibitor development. Blood 98: 248 250 .

46. Vidal F, Julià A, Altisent C, Puig L, Gallardo D (2005) Von Willebrand gene tracking by single-tube automated fluorescent analysis of four short tandem repeat polymorphisms. Thromb Haemost 93: 976-981.

47. Kasatkar P, Shetty S, Ghosh K (2014) Prenatal diagnosis in severe von Willebrand disease families from India using combination of phenotypic and genotypic assays. Prenat Diagn 34: 377-381.

48. Keeling D, Tait C, Makris M (2008) Guideline on the selection and use of therapeutic products to treat haemophilia and other hereditary bleeding disorders. A United Kingdom Haemophilia Center Doctors' Organisation (UKHCDO) guideline approved by the British Committee for Standards in Haematology. Haemophilia 14: 671-84.

49. Haj MA, Murch N, Bowen DJ, Sati HI, Beddal A, et al. (2006) Cefotaxime as the potential cause of transient acquired von Willebrand syndrome. Eur J Haemato 76: $440-443$

50. Rodgers SE, Lloyd JV, Mangos HM, Duncan EM, McRae SJ (2011) Diagnosis and management of adult patients with von Willebrand disease in South Australia. Semin Thromb Hemost 37: 535-541.

51. Meiring M, Coetzee M, Kelderman M, Badenhorst P (2011) Laboratory diagnosis and management of von Willebrand disease in South Africa. Semin Thromb Hemost 37: 576-580.

52. Favaloro EJ (2011) Von Willebrand disease: local diagnosis and management of a globally distributed bleeding disorder. Semin Thromb Hemost 37: 440-455.

53. Federici AB, Bucciarelli P, Castaman G, Baronciani L, Canciani MT, et al (2011) Management of inherited von Willebrand disease in Italy: results from the retrospective study on 1234 patients. Semin Thromb Hemost 37: 511-521.

54. Awidi AS (1992) A study of von Willebrand's disease in Jordan. Ann Hematol 64: 299-302

55. Ahmad F, Kannan M, Ranjan R, Bajaj J, Choudhary VP, et al. (2008) Inherited platelet function disorders versus other inherited bleeding disorders: an Indian overview. Thromb Res 121: 835-841.

Citation: Mohanty D, Shetty S (2014) Von Willebrand Disease: An Update. Blood Disorders Transf 5: 238. doi: 10.4172/2155-9864.1000238 